\title{
UMA PROPOSTA DE MODELO PARA A FORMAÇÃO DE PRECEDENTE: EXPOSIÇÃO E FUNCIONALIDADE A PARTIR DE EXAME DE CASO ${ }^{1}$
}

\section{A MODEL PROPOSAL FOR PRECEDENT FORMATION: EXPOSURE AND FUNCTIONALITY FROM CASE EXAMINATION}

Augusto Tanger Jardim Advogado. Professor de graduação e especialização da Fundação Escola Superior do Ministério Público do Rio Grande do Sul - FMP. Doutor em Direito junto à Universidade Federal do Rio Grande do Sul - UFRGS. Mestre em Direito pela Pontifícia Universidade Católica do Rio Grande do Sul - PUCRS. Porto Alegre, Rio Grande do Sul, Brasil. E-mail: augusto_jardim@yahoo.com.br

Isadora da Silva Gross Advogada. Pós-Graduanda em Direito Civil e Processo Civil na Fundação Escola Superior do Ministério Público - FMP. Pesquisadora do Grupo de Estudos "Processo Civil e Estado Constitucional" da Universidade Federal do Rio Grande do Sul UFRGS, coordenado pelo Prof. Dr. Daniel Mitidiero. Pesquisadora do Grupo de Pesquisa "Teoria do Direito: da academia à prática” da Fundação Escola Superior do Ministério Público - FMP, coordenado pelo Prof. Dr. Francisco Motta. Porto Alegre, Rio Grande do Sul, Brasil. E-mail: isadoragross@hotmail.com.

RESUMO: O presente artigo busca definir o modo de formação dos precedentes a partir da decisão, propondo um modelo de aferição. O estudo inicialmente debruça-se sobre a dupla indeterminação do direito, a fim de descobrir se precedente é, ou não, a própria decisão. Num segundo momento, se apresenta uma proposta de modelo a partir da análise de pressupostos em uma dupla dimensão: uma interna à decisão e outra externa à decisão. Por

\footnotetext{
${ }^{1}$ Artigo recebido em 06/10/2020 e aprovado em 28/10/2020.
} 
fim, enfrenta-se o problema da decisão plural, desde uma perspectiva teórica, até o estudo analítico tomando como caso exemplificativo os fundamentos decisórios expostos no julgamento do HC 126.292, do STF. A partir dos pressupostos traçados, conclui-se que a delimitação clara dos fundamentos decisórios se mostra importante à formação (mas também à aplicação) dos precedentes e, em última instância, à unidade do direito.

PALAVRAS-CHAVE: Indeterminação do direito. Formação dos precedentes. Modelo de aferição. Decisão plural. Interpretação da decisão plural.

ABSTRACT: This article seeks to define the way in which precedents are formed from the decision, proposing a measurement model. The study initially focuses on the double indeterminacy of law, in order to find out whether precedent is, or not, the decision itself. Secondly, a model proposal is presented based on the analysis of assumptions in a double dimension: one internal to the decision and the other external to the decision. Finally, the problem of the plural decision is faced, from a theoretical perspective, to the analytical study taking as an example the decision fundamentals exposed in the judgment of HC 126.292, of the Supreme Federal Court. From the assumptions taken, it is concluded that the clear delimitation of the decision fundamentals is important to the formation (but also to the application) of precedents and, ultimately, to the unity of law.

KEY WORDS: Indeterminacy of law. Formation of precedents. Measurement model. Plural decision. Interpretation of the plural decision.

\section{INTRODUÇÃO}

O tema do precedente embora já chamasse a atenção dos estudiosos do processo civil, tem recebido tratamento ainda mais abrangente diante do seu reconhecimento no Código de Processo Civil de $2015^{2}$. Entretanto, o ponto que mais tem despertado interesse e controvérsia diz respeito à medida da vinculatividade a que as decisões posteriores estão

${ }^{2}$ O Código de Processo Civil de 1973 mencionava o precedente no caput seu art. 479 que dispunha que "O julgamento, tomado pelo voto da maioria absoluta dos membros que integram o tribunal, será objeto de súmula e constituirá precedente na uniformização da jurisprudência”. Saliente-se que tal dispositivo estava inserido no título do código que tratava da uniformização da jurisprudência. Como se observa, a noção acerca do precedente foi modificada drasticamente, se considerado o contexto atual da doutrina. 
submetidas aos precedentes. Para além da importância da temática propriamente dita, esse fenômeno é estimulado pelo texto legal do Código. Isso porque o Código não esclarece (como não poderia deixar de ser na medida em que se trata de tema de teoria do direito e não de processo civil), mas indica quais técnicas de julgamento (art. 927) possuem força ope legis vinculante e como deverá a sentença ser motivada diante da invocação de um precedente.

O reflexo prático disso é, como observa Câmara, que a doutrina "que tem se debruçado sobre o tema dos precedentes volta sua atenção, ao menos como regra geral, para sua aplicação, mas não para sua formação". ${ }^{3}$ É exatamente neste contexto que o presente artigo pretende contribuir.

Explicitado que o este ensaio não se ocupa da vinculação do precedente, é necessário tornar claro quais problemas que se pretende enfrentar e como se pretende superá-los.

Um primeiro problema que se apresenta quanto à formação dos precedentes é definir se ele corresponde à própria decisão produzida (ou parte), ou se ele é o resultado da interpretação de uma determinada decisão (decisão sobre a decisão). Este ponto, será enfrentado à luz da compreensão de que o direito é duplamente indeterminado tendo por referencial teórico, em especial, Riccardo Guastini, no campo da teoria da argumentação, e Daniel Mitidiero e Luiz Guilherme Marinoni, no campo da teoria dos precedentes.

Um segundo problema a ser investigado diz respeito a quais as decisões que se mostram aptas a formar um precedente. Aqui, o trabalho apresenta um modelo de aferição das condições necessárias para tanto, levando em conta fatores externos e interno à decisão.

Ao final, busca-se demonstrar como a construção concebida opera diante de um dos problemas mais sensíveis, em especial no Brasil, na formação dos precedentes: as decisões plurais. A intenção com esta escolha é submeter a teste o modelo proposto da forma mais rigorosa possível, tomando como referência o HC 126.292 julgado pelo Supremo Tribunal Federal.

\section{DA INDETERMINAÇÃO DO DIREITO À FORMAÇÃO DO PRECEDENTE}

${ }^{3}$ CAMARA, Alexandre Freitas. Levando os padrões decisórios a sério: formação e aplicação de precedentes e enunciados de súmula. São Paulo: Atlas, 2018, p. 178. 
A evolução da teoria da interpretação fez com que a doutrina passasse a se preocupar com a (dupla) indeterminação do direito ${ }^{4}$, compreendendo paulatinamente que o formalismo teórico ${ }^{5}$ já não era adequado, nem suficiente para outorgar segurança jurídica às pessoas, fazendo com que se desenvolvesse o ceticismo e suas ramificações. ${ }^{6}$

Segundo essa perspectiva, compreende-se por "norma" o produto da atividade interpretativa ${ }^{7}$, notadamente alcançada a partir da argumentação jurídica que por sua vez é "o conjunto de justificações que são aduzidas em favor de tal decisão". ${ }^{8}$ Portanto, norma não se confunde com texto, pois aquela é construída a partir da interpretação sistemática de textos normativos. ${ }^{9}$

No entanto, levando em consideração esses pressupostos e, igualmente, que "o Direito é o avesso da arbitrariedade" 10 , a dita escolha do significado do texto normativo obrigatoriamente deve ser pautada por um discurso racional, onde a argumentação jurídica

\footnotetext{
${ }^{4}$ Segundo Guastini (GUASTINI, Riccardo. Interpretare e Argomentare. Milano: Giuffrè, 2011, p. 39-61), assim compreende-se porque: (a) o ordenamento jurídico é indeterminado enquanto tal (haja vista que não é possível saber, aprioristicamente, quais as normas existem nele, quais as normas pertencem a ele ou quais as normas sejam nele vigentes), bem como (b) cada norma por si mesma é indeterminada. Tal constatação decorre da equivocidade dos textos normativos, dos mais diversos gêneros, como a ambiguidade, a complexidade, a implicação, a defectibilidade, e o problema dos enunciados taxativos ou exemplificativos.O problema da equivocidade está associado ao fato de que a interpretação no Direito demanda a análise de dispositivos que possuem mais de um significado decorrente dessas características indicadas anteriormente, enquanto o problema da vagueza decorre da circunstância de que, "embora saiba o conteúdo da norma, o intérprete pode não saber exatamente quais fatos recaem no seu âmbito de aplicação, dado não existirem apenas casos fáceis, mas também casos difíceis", fruto da incapacidade linguística de "confinar o futuro em modelos concebidos no passado", bem como em razão de que a equivocidade "pode ser provocada ou aumentada, intencional ou gratuitamente, pelo Poder Legislativo, por meio da instituição de normas com diferentes tipos de indeterminação, como princípios jurídicos ou regras contendo cláusulas gerais" (ÁVILA, Humberto. Função da ciência do direito tributário: do formalismo epistemológico ao estruturalismo argumentativo. Revista Direito Tributário Atual, n. 29, p. 181-204, 2013, p. 191). Ressalta-se, ainda, que o reconhecimento da indeterminação do direito como um problema a ser enfrentado através da interpretação já tinha sido reconhecido, inclusive, por Hans Kelsen quando elencou que a indeterminação do ato de aplicação do Direito se daria de forma "intencional" e "não-intencional" (KELSEN, Hans. Teoria Pura do Direito. Tradução: João Baptista Machado. $8^{a}$ ed. São Paulo: WMF Martins Fontes, 2009, p. 387-390).

${ }^{5}$ Por formalismo teórico se entende a teoria da interpretação segundo a qual "(a) a interpretação é uma atividade não de decisão, mas de conhecimento; (b) o discurso interpretativo é, portanto, um discurso descritivo, ou seja, aquele do qual dos seus enunciados pode sensatamente predicar a verdade e a falsidade; (c) há para toda norma, uma e só uma única interpretação verdadeira". GUASTINI, Riccardo. Das Fontes às Normas. Tradução: Heleno Taveira Tôrres. São Paulo: QuartierLatin, 2005, p. 160-165.

${ }^{6}$ MITIDIERO, Daniel. Precedentes: da persuasão à vinculação. $2^{\mathrm{a}}$ ed. São Paulo: Revista dos Tribunais, 2018, p. 55.

${ }^{7}$ GUASTINI, op. cit., p. 131.

${ }^{8}$ GUASTINI, op. cit., p. 154.

${ }^{9}$ ÁVILA, Humberto. Teoria dos Princípios: da definição à aplicação dos princípios jurídicos. $19^{\mathrm{a}}$ ed. São Paulo: Malheiros, 2019, p. 50.

${ }^{10}$ MITIDIERO, Daniel. Precedentes: da persuasão à vinculação. $2^{\mathrm{a}}$ ed. São Paulo: Revista dos Tribunais, 2018, p. 67.
} 
seja traçada mediante justificação interna (organização lógico-formal das premissas) e externa (correção das premissas). ${ }^{11}$

Amalgamando-se a indeterminabilidade do direito à função interpretativa das Cortes Supremas ${ }^{12}$, tem-se que estas no ato decisório expressam a motivação que justifica a escolha de um dentre os resultados interpretativos possíveis - mediante enunciação de argumentos racionais em apoio à hipótese eleita, em detrimento das demais. ${ }^{13}$ Contudo, em a norma sendo uma escolha interpretativa da disposição legal (na medida em que é falso que cada disposição corresponda a somente uma norma ou que uma norma corresponda a

\footnotetext{
11 Segundo Michele Taruffo, “A análise estrutural do raciocínio do juiz deve partir necessariamente da individualização da sua função típica. Enquanto, porém, a estrutura do raciocínio decisório é condicionada pelo fato de que o fim por esse buscado é a obtenção da decisão, a estrutura da motivação é condicionada pelo fato de que essa busca justificar a decisão. No curso desta pesquisa foram encontradas numerosas confirmações episódicas dessa distinção e essas já seriam suficientes para fundar sua validade geral. Essa encontra, porém, mais uma base se se entende que se trata de uma manifestação particular, concernente ao raciocínio do juiz, de um princípio válido a respeito de todo e qualquer tipo de procedimento racional. Essa consiste na fundamental distinção que a metodologia lógica e científica traçou entre context of discovery e context of justification (ou of explanation), entendendo-se o primeiro como o procedimento que conduz à formulação de um determinada solução para um problema e o segundo como o procedimento dirigido a demonstrar, justificando-a, a validade dessa solução". Acrescenta ainda que "Isso permite precisar posteriormente a relação existente entre o particular context of discovery constituído pelo procedimento decisório e o context of justification constituído pela motivação: esses são diferentes não somente do ponto de vista estrutural, mas também do ponto de vista fenomenológico, no sentido de que o primeiro é uma atividade e o segundo um discurso que, além de tudo, não é nem mesmo o resultado linguístico dessa atividade" (TARUFFO, Michele. A motivação da sentença civil [La motivazione della sentenza civile - 1975]. Trad. Daniel Mitidiero, Rafael Abreu, Vitor de Paula Ramos. São Paulo: Marcial Pons, 2015, p. 196-197). Reconstruindo a origem da distinção entre contexto de decisão e contexto de justificação proposto por Michele Taruffo, Otávio Verdi Motta afirma que "Wassestrom refere-se a process of discovery e process of justification: "I will refer to the procedure by with a conclusion is reached as the process of discovery, and to the procedure by which a conclusion is justified as the process of justification" ([WASSERSTROM, Richard A. The judicial decision: toward a theory of legal justification. Stanford: Stanford University Press, 1961], p. 27). Alexy igualmente fala de process of discovery e process of justification ([ALEXY, Robert. Teoria da argumentação jurídica - A teoria do discurso racional como teoria da fundamentação jurídica. 3. ed. Trad. Zilda Hutchinson Schild Silva. Rio de Janeiro: Forense, 2011], p. 227). Taruffo, por sua vez, refere-se a context of discovery e context of justification ([ $L a$ motivazione della sentenza civile. Padova: Cedam, 1975], p. 214)" (MOTTA, Otávio Verdi. Justificação da decisão judicial: a elaboração da motivação e a formação de precedente. São Paulo: Revista dos Tribunais, 2015, p. 141).

${ }^{12}$ MITIDIERO, Daniel. Cortes Superiores e Cortes Supremas: do controle à interpretação, da jurisprudência ao precedente. $3^{\mathrm{a}}$ ed. São Paulo: Revista dos Tribunais, 2017.

${ }^{13}$ Nesse sentido, remete-se à doutrina de Michele Taruffo: "Per ogni scelta il modulo fondamentale è quello della formulazione di ipotesi alternative per poi scegliere quella 'migliore' secondo criteri di decisione adeguati e possibilmente razionali. La motivazione è finalizzata a giustificare le scelte, che presuppone già compiute. Il suo modulo fondamentale non è quello della scelta fra alternative, ma quello dell'enunciazione di argomenti razionali a sostegno dell'ipotesi decisoria assunta come 'migliore'." (TARUFFO, Michele. Il Controllo di Razionalità della Decisione fra Logica, Retorica e Dialettica. Revista de Processo, v. 143, jan., p.65, 2007).
} 
somente uma disposição ${ }^{14}$ ) a motivação do ato decisório se torna a forma de controle da racionalidade das razões utilizadas pela Corte para justificar sua decisão. ${ }^{15}$

Com isso, as decisões das Cortes Supremas servem como forma de elucidar o direito, a partir da interpretação e prática argumentativa, definindo o "sentido adequado do texto legal diante de determinadas circunstâncias de fato e num determinado momento histórico". ${ }^{16}$ Em outras palavras, a reconstrução semântica efetivada através desse processo interpretativo resulta na especificação de um sentido normativo anteriormente indeterminado, promovendo um "estreitamento da moldura normativa". ${ }^{17}$

Até este ponto, transitando da teoria para a realidade prática, tem-se um caso (questão fático-jurídica) que obteve uma resposta por um órgão do estado com autoridade para dar a última palavra sobre a questão. Dito de outra forma, o Estado foi chamado a responder sobre qual a forma mais adequada de comportamento esperado diante de uma determinada questão, levando em conta a indeterminação (linguística) do direito, e apontou uma solução.

A pergunta que nasce neste momento envolve saber se quando é proferida a decisão o precedente já está necessariamente e “automaticamente” formado, ou se a decisão é ponto de partida para tanto.

Inicialmente, parece-nos impreciso considerar que a própria decisão produzida corresponda ao precedente. ${ }^{18}$ Em primeiro lugar, porque nem tudo que faz parte da decisão integra a ratio decidendi de um precedente (configurando obter dictum), mas virá a integrála somente as suas razões universalizáveis. Em segundo lugar, porque, ainda que se considere uma parte da decisão apta à formação do precedente, é impossível que a identificação da aludida "parte da decisão" não seja (re)interpretada por quem pretende fazêla valer como precedente. Em outras palavras, assim como o texto legal (com pretensão de

\footnotetext{
${ }^{14}$ GUASTINI, Riccardo. Interpretare e Argomentare. Milano: Giuffrè, 2011, p. 64.

${ }^{15}$ TARUFFO, Michele. Il Controllo di Razionalità della Decisione fra Logica, Retorica e Dialettica. Revista de Processo, v. 143, jan., p.65, 2007. Ressaltando o controle da escolha interpretativa através da motivação e argumentação: TARELLO, Giovanni. L'interpretazione della Legge. Milano: Giunffrè, 1980, p. 67-75.

${ }^{16}$ MARINONI, Luiz Guilherme. Julgamento nas Cortes Supremas: precedente e decisão do recurso diante do novo CPC. Ed. São Paulo: Revista dos Tribunais, 2015, p. 18.

${ }^{17}$ MITIDIERO, op. cit., p. 84.

${ }^{18}$ Neste sentido, compreendendo o precedente como a própria decisão judicial tomada à luz de um caso concreto: DIDIER JR., Fredie; BRAGA, Paula Sarno; OLIVEIRA, Rafael Alexandria de. Curso de Direito Processual Civil: teoria da prova, direito probatório, decisão, precedente, coisa julgada e tutela provisória. 14 ${ }^{\mathrm{a}}$ ed. Salvador: JusPodivm, 2019, p. 549.
} 
generalidade e abstração) demanda adscrição de sentido pelo seu intérprete, a decisão (texto, em geral, com pretensão de aplicação do direito geral e abstrato) demanda interpretação (adscrição de sentido) a fim de, a partir dele, serem apontadas razões universalizáveis (pretensão de generalidade e abstração). ${ }^{19}$

A ratio decidendi é extraída justamente na aplicação do precedente no casoatual $^{20}$, de modo que o significado do precedente é delineado pelas razões que levaram à fixação do dispositivo contidas na fundamentação da decisão. ${ }^{21}$ A atividade interpretativa que tem por objeto o precedente resulta a norma geral que constitui a ratio decidendi. ${ }^{22}$ Já sob outra perspectiva, ela pode ser observada como formativa do próprio conceito de precedente, na medida em que este qualitativamente é definido como "razões jurídicas necessárias e suficientes que resultam da justificação das decisões prolatadas pelas Cortes Supremas". ${ }^{23}$ A ratio decidendi, portanto, "não expressa o que o tribunal decidiu, mas por que assim decidiu". ${ }^{24}$

Assim, parece necessário se ter clareza de que o precedente é resultado de um processo interpretativo de uma determinada decisão. Contudo, também é importante se ter presente que não é qualquer decisão que tem o condão de servir à formação de um precedente. É exatamente disso que trata o próximo tópico.

\section{DECISÕES QUE PERMITEM A FORMAÇÃO DE PRECEDENTE: UMA PROPOSTA DE MODELO DE AFERIÇÃO}

\footnotetext{
${ }^{19}$ Saliente-se que este processo de interpretação e atribuição de significado do geral ao particular e do particular ao geral, uma vez que forma o precedente, se reproduz no campo da aplicação do precedente. Pois, ao aferir as razões universalizáveis na aplicação do precedente (seja de forma persuasiva [para quem cogita dessa possibilidade] seja de forma vinculante) o juiz também se vale da interpretação para atribuir sentido às razões universalizáveis (vazadas em texto). É exatamente este processo que permite a evolução do precedente (superação, distinção etc.). Se isso está certo, então está-se autorizado a concluir que há uma redução (jamais eliminação), por assim dizer, do "grau" de indeterminabilidade do Direito, a partir da decisão.

${ }^{20}$ ZANETI JR., Hermes. $O$ Valor Vinculante dos Precedentes: teoria dos precedentes normativos formalmente vinculantes. $4^{\mathrm{a}}$ ed. Salvador: JusPodivm, 2019, p. 324.

${ }^{21}$ MARINONI, Luiz Guilherme. Precedentes Obrigatórios. 6 a ed. São Paulo: Revista dos Tribunais, 2019, p. 158.

${ }^{22}$ CHIASSONI, Pierluigi. Il Precedente Giudiziale: tre esercizi di disincanto. In.: COMANDUCCI, Paolo; GUASTINI, Riccardo (Coord.). Analisi e Diritto: ricerche di giurisprudenza analitica. Torino: G. Giappichelli Editore, 2004, p. 89-90.

${ }^{23}$ MITIDIERO, Daniel. Precedentes: da persuasão à vinculação. $3^{\mathrm{a}}$ ed. São Paulo: Revista dos Tribunais, 2018 , p. 98.

${ }^{24}$ FERRAZ, Thaís Schilling. A Construção da Motivação nas Decisões Colegiadas: o importante papel da majority opinion em um sistema de precedentes. Revista de Processo, v. 282, ago., p.435-451, 2018.
} 
Como já foi exposto, a decisão deve ter determinados atributos para que constitua um precedente. Optamos por classificar os pressupostos para formação do precedente em duas dimensões:(a) uma externa à decisão e (b) outra interna à decisão.

A dimensão externa atine a questões que não dizem respeito propriamente à decisão proferida, mas a fatores associados (a.1) aos órgãos responsáveis por sua produção (critério qualitativo ou institucional) e (a.2) ao resultado obtido pela decisão colegiada (critério quantitativo ou majoritário).

No que diz respeito ao critério qualitativo pertencente à dimensão externa da decisão, tem-se que somente as Cortes $\operatorname{Supremas}^{25}$ possuem função institucional para produzir decisões aptas a servir à formação do precedente. ${ }^{26}$

Por outro viés, a decisão que servirá à formação do precedente deverá ser produzida a partir do consenso, por unanimidade ou por maioria, dos membros do seu órgão prolator. Esse é um critério que, independentemente do conteúdo da decisão propriamente dita (daí porque considerado na dimensão externa), leva em consideração critérios quantitativos da tomada de decisão. Importante referir que o alcance do quórum necessário (que varia de acordo com a composição do órgão encarregado da decisão) para que uma determinada questão possa a vir servir de base para a formação de um precedente deve guardar correlação com o tema do precedente propriamente dito, e não necessariamente com o resultado final do julgamento. Dito de outro modo, exemplificativamente, num recurso provido por três votos a dois, num colegiado formado por cinco julgadores, somente será possível extrair a ratio decidendi se os três votos vencedores sustentarem o mesmo

\footnotetext{
${ }^{25}$ Aqui adota-se a compreensão e a classificação proposta por Daniel Mitidiero. Segundo o autor, a função das Cortes de Justiça - no Brasil, Tribunais de Justiça e Tribunais Regionais Federais - é prolatar decisões justas e efetivá-las adequadamente, resolvendo as controvérsias para viabilizar a proteção de direitos individuais ou transindividuais suscitados pelas partes. Ou seja, as Cortes de Justiça são vocacionadas à prolação de decisões para promoção da tutela dos direitos numa dimensão particular (MITIDIERO, Daniel. Cortes Superiores $e$ Cortes Supremas: do controle à interpretação, da jurisprudência ao precedente. $3^{a}$ ed. São Paulo: Revista dos Tribunais, 2017, p. 28-39). Por outro lado, a função das Cortes Supremas - no Brasil, Supremo Tribunal Federal e Superior Tribunal de Justiça - é dar unidade ao Direito mediante adequada interpretação dos textos normativos, notadamente a partir do julgamento de casos a ela apresentados, sendo competente para orientar a aplicação do Direito por intermédio de suas decisões, cujas razões (precedentes) vinculam toda sociedade civil e todos os órgãos do Poder Judiciário (Ibid., p. 65-92).

${ }^{26}$ Nesse sentido, entre outros: TARUFFO, Michele. Precedente e Jurisprudência. Revista de Processo, v. 199, set., p.139, 2011; MARINONI, Luiz Guilherme. Precedentes Obrigatórios. $6^{\mathbf{a}}$ ed. São Paulo: Revista dos Tribunais, 2019; MITIDIERO, Daniel. Precedentes: da persuasão à vinculação. $3^{\mathrm{a}}$ ed. São Paulo: Revista dos Tribunais, 2018; ZANETI JR., Hermes. O Valor Vinculante dos Precedentes: teoria dos precedentes normativos formalmente vinculantes. $4^{\mathrm{a}}$ ed. Salvador: JusPodivm, 2019.
} 
fundamento. Portanto, a decisão deve ser majoritária não somente quanto à solução do caso, mas também necessariamente quanto aos fundamentos determinantes expostos na justificativa dos votos. ${ }^{27}$

Já a dimensão interna relaciona-se com a própria decisão devendo se fazer presente a (b.1.1) delimitação dos fatos, (b.1.2) a enunciação das razões universalizáveis e a (b.1.3) constituição de acréscimo no ordenamento jurídico. ${ }^{28}$

O primeiro elemento relaciona-se com a necessidade de delimitação dos fatos do caso em julgamento. Inicialmente, o dever de expor os fatos é relevante sob o ponto de vista da legitimação da conclusão tomada pela Corte, na medida em que a abstração dos fatos relevantes nos quais a conclusão se baseia pode tornar a decisão arbitrária. ${ }^{29}$ Também, encontra-se na exposição factual a delimitação do alcance da ratio decidendi. Além disso, dita delimitação tem como objetivo possibilitar a aplicação do precedente ao caso subsequente. Isso porque um sistema de precedentes racional reclama a comparação entre casos mediante analogia das duas fattispecie $\operatorname{concretas}^{30}$, de modo que a aplicação da ratio decidendi “demanda a individualização dos pressupostos fáticos-jurídicos essenciais que dão vida aos casos e a busca por semelhanças ou distinções relevantes". ${ }^{31}$

$\mathrm{O}$ segundo elemento remete à necessidade de enunciação clara das razões jurídicas universalizáveis utilizadas à solução do caso. Essas razões estão inseridas dentro do discurso justificativo, sobretudo (no que tange à estrutura da motivação) no segundo nível de justificação, onde o intérprete deve justificar os enunciados escolhidos para logicamente conduzir à decisão, a partir de pressupostos racionais. ${ }^{32}$ Em síntese, é na motivação das

\footnotetext{
${ }^{27}$ Nesse sentido: MARINONI, Luiz Guilherme. Precedentes Obrigatórios. $6^{\mathrm{a}}$ ed. São Paulo: Revista dos Tribunais, 2019, p. 154; MITIDIERO, Daniel. Precedentes: da persuasão à vinculação. $3^{a}$ ed. São Paulo: Revista dos Tribunais, 2018, p. 98.

${ }^{28}$ Preferiu-se fazer referência à estrutura mínima da decisão, a fim de delimitar aquilo que se compreende como essencial e inafastável à formação do precedente. Entretanto, poder-se-ia elencar outros elementos importantes, sobretudo para futura aplicação do precedente, como, por exemplo, as informações básicas sobre o caso, o histórico processual, o esclarecimento de todas as questões legais postas em julgamento, bem como as justificativas à utilização das razões à solução do caso. Sobre esses elementos, ver: FINE, Toni M. Introdução ao sistema jurídico Anglo-Americano. Tradução: Eduardo Saldanha. São Paulo: VWF Martins Fontes, 2011, p. 70-76.

${ }^{29}$ GOODHART, Arthur. Determining the Ratio Decidendi of a Case. Yale Law Journal, v. 40, 1930.

${ }^{30}$ TARUFFO, Michele. Precedente e Jurisprudência. Revista de Processo, v. 199, set., p.139, 2011.

${ }^{31}$ MITIDIERO, Daniel. Precedentes: da persuasão à vinculação. $3^{\mathrm{a}}$ ed. São Paulo: Revista dos Tribunais, 2018, p. 112.

${ }^{32}$ Sobre a estrutura da motivação e os dois níveis de justificação, ver: TARUFFO, Michele. A motivação da sentença civil [La motivazione della sentenza civile - 1975] Tradução: Daniel Mitidiero Rafael Abreu e Vitor de Paula Ramos. São Paulo: Marcial Pons, 2015, p. 234-266.
} 
decisões das Supremas Cortes que são delineadas razões racionalmente sustentadas e, portanto, generalizáveis a casos iguais ou semelhantes, de modo que desenhá-las claramente é essencial à extração da ratio decidendi.

O último elemento diz respeito à necessidade de inovação, ou seja, deve constituir um acréscimo ao ordenamento jurídico. Isso significa que não basta que a decisão delimite os fatos e desenhe de forma clara as razões à solução do caso, se ela apenas afirmar o texto da lei ou replicar um precedente. ${ }^{33}$ Diante disso, deve a decisão adscrever sentido aos textos normativos de modo a agregar o desenvolvimento do direito.

Traçados os pressupostos para que de uma decisão se extraia uma razão universalizável, pode-se enfrentar o problema das decisões plurais, de modo a abordar de forma crítica como a estrutura da decisão se apresenta como um impasse à formação e à interpretação dos precedentes.

\section{O PROBLEMA DAS DECISÕES PLURAIS NA FORMAÇÃO DO PRECEDENTE}

Conforme já se demonstrou no presente trabalho, uma decisão deve atender determinados pressupostos à formação de precedente, os quais não estão, de modo algum, relacionados à técnica de julgamento - daí que se pode concluir ser plenamente possível a formação de precedente nos julgamentos de Recursos Extraordinários não repetitivos, por exemplo. Dentro desses aspectos da decisão que levam à possibilidade de que esta forme um precedente está a necessidade de consenso, por unanimidade ou por maioria, quanto ao fundamento determinante à solução do caso.

Assim, se o consenso é um pressuposto para que se possa extrair um precedente da decisão, torna-se inafastável o enfrentamento do problema decorrente da chamada “decisão plural” (plurality decision). A decisão plural caracteriza-se por ser "uma decisão majoritária que contém em si duas rationes ou fundamentos determinantes, sem com que qualquer deles esteja amparado pela maioria do colegiado". ${ }^{34}$ Em outras palavras, trata-se

\footnotetext{
33 Nesse sentido: ZANETI JR., Hermes. O Valor Vinculante dos Precedentes: teoria dos precedentes normativos formalmente vinculantes. $4^{\mathrm{a}}$ ed. Salvador: JusPodivm, 2019, p. 329; MARINONI, Luiz Guilherme. Precedentes Obrigatórios. $6^{\text {a }}$ ed. São Paulo: Revista dos Tribunais, 2019, p. 154-155.

${ }^{34}$ MARINONI, Luiz Guilherme. Julgamento nas Cortes Supremas: precedente e decisão do recurso no novo CPC. Ed. São Paulo: Revista dos Tribunais, 2015, p. 39.
} 
de uma decisão com fundamento não aceitável para a maioria dos julgadores, mas com sua solução majoritária apoiada pela combinação de duas ou mais separate opinions. ${ }^{35}$

O problema central da decisão plural é a indeterminação ou propriamente a inexistência de uma ratio decidendi ${ }^{36}$, diante da coexistência de diversas frentes argumentativas que expõem razões autônomas, necessárias e suficientes à solução do caso, sem que haja consenso da maioria quanto a elas. Os esforços pela busca de um elemento vinculante nas decisões cujos fundamentos são firmados pela minoria do colegiado levaram à definição de critérios que visam possibilitar a extração da ratio decidendi como, por exemplo, o "narrowest grounds". 37 Conforme leciona Luiz Guilherme Marinoni, o "narrowest grounds" foi um critério adotado pela Suprema Corte dos Estados Unidos baseado na premissa de que, quando a Corte decide um caso e nenhum fundamento é compartilhado pela maioria do colegiado, "a ratio deve ser vista como a posição adotada por aqueles que concorrem ao julgamento em termos de "narrowest grounds", de modo que "a 'narrowest opinion' deve representar o denominador comum do raciocínio da Corte ou deve incorporar a posição implicitamente aprovada ao menos pelos cinco Justices que compartilham a decisão plural". ${ }^{38}$

Porém, muito embora a técnica utilizada seja exitosa em alguns casos, não é capaz de solucionar completamente a celeuma da decisão plural, na medida em que existem decisões que são formadas por diversas razões autônomas que não encontram qualquer ponto de contato. ${ }^{39}$ Poder-se-ia pensar, como forma de exemplificação, numa decisão que declara

\footnotetext{
${ }^{35}$ DAVIS, John F.; REYNOLDS, William L. JuridicalCripples: Pluralityopinions in the supremecourt. Duke Law Journal, v. 59, 1974, p. 59.

36“ [...] o qualitativo plural não se destina a indicar vários julgadores, mas uma pluralidade de fundamentos ou rationes - nenhum deles sustentado pela maioria do colegiado - que se insere numa decisão em que o resultado é compartilhado pela maioria. Essa pluralidade de fundamentos impede que se extraia da decisão uma ratio decidendi, ou ao menos uma ratio decidendi clara" (MARINONI, op. cit., p. 39).

${ }^{37}$ Também chamado de "Marks test" por ter sido um argumento utilizado no julgamento do caso Marks $v$. United States representando 'a conscious attempt to end the confusion surrounding plurality decisions' precedential value". HOCHSCHILD, Adam S. The Modern Problem of Supreme Court Plurality Decision: Interpretation In Historical Perspective. Washington University Journal of Law \& Policy, vol. 4., 2000, p. 279. ${ }^{38}$ MARINONI, Luiz Guilherme. Julgamento nas Cortes Supremas: precedente e decisão do recurso no novo CPC. Ed. São Paulo: Revista dos Tribunais, 2015, p. 72.

${ }^{39}$ Veja-se que o modelo de decisão per curiam também não é alheio ao problema enunciado, porque "a latent danger inherent in the use of the per curiam technique is that it could easily become a wonderfully attractive device for postponing difficult decisions". Isso acontece na medida em que a Corte pode expor um enunciado comum - a solução do caso - sem concordar majoritariamente sobre as razões que embasam a decisão, postergando a definição de casos difíceis. Pode-se encontrar no caso Furman v. Georgia um excelente exemplo, pois nessa ocasião, em que pese a opinião per curiam do Tribunal tenha sustentado que a pena de morte era inconstitucional, não foram estabelecidas de forma clara em quais circunstâncias a aplicação dessa pena seria
} 
incidentalmente a inconstitucionalidade de uma lei, de modo a deixar de aplicá-la no caso em apreciação, com base nos seguintes argumentos: (a) a lei é formalmente inconstitucional, uma vez que editada em desconformidade com as regras constitucionais de competência, (b) a lei é materialmente inconstitucional, porquanto contrária ao direito fundamental " $\mathrm{x}$ " expressamente tutelado pela Constituição, e (c) a lei é materialmente inconstitucional, pois contrária ao direito fundamental "y" expressamente tutelado pela Constituição. Suponha-se que o colegiado seja formado por cinco julgadores e, destes, dois tenham sustentado o argumento "a", dois tenham sustentado o argumento " $b$ " e um tenha fundamentado seu voto com base na premissa “c". Nesse caso resta evidenciada a pluralidade, com a impossibilidade de aplicação do "narrowest grounds", pois as razões são absolutamente distintas e capazes de autonomamente sustentar a solução do caso.

Justamente diante da celeuma decorrente da prolação de decisões plurais, somada com a opção legislativa na elaboração do artigo 927, do Código de Processo Civil (porquanto, ao mesmo tempo, disse mais e menos do que deveria dizer ${ }^{40}$ ) que se encontra quiçá o maior problema da aplicação dos precedentes na Justiça Civil brasileira: definir o elemento vinculante das decisões proferidas pela Suprema Corte.

Assim, o Supremo Tribunal Federal, que tem o papel de intérprete final da Constituição, devendo atuar proativamente, com o objetivo de orientar a aplicação do direito, materializando a tutela dos direitos numa dimensão geral, tudo isso em razão da compreensão de que a atividade jurisdicional é pautada na reconstrução da ordem jurídica a partir da outorga de sentido aos textos normativos, acaba por perder excelentes oportunidades de exercer plenamente sua competência, conforme demonstrar-se-á empiricamente.

\section{A FUNCIONALIDADE DO MODELO PROPOSTO A PARTIR DA ANÁLISE DO HC126.292 JULGADO PELO SUPREMO TRIBUNAL FEDERAL}

Reiteradas decisões proferidas pelo Supremo Tribunal Federal deixam de apresentar elementos necessários à formação de precedentes. Nesse contexto, essa Suprema

inconstitucional - para além das especificidades daquele caso. DAVIS, John F.; REYNOLDS, William L. Juridical Cripples: Plurality opinions in the supreme court. Duke Law Journal, v. 59, 1974, p. 83.

40 "Em primeiro lugar, o art. 927, I, não prevê propriamente hipótese de precedente. [...] Em segundo lugar, deixa de arrolar hipóteses em que pode haver a formação de precedentes e arrola hipóteses em que pode não haver a formação de precedentes. [...] Em terceiro lugar, escapa ao legislador que precedentes e súmulas estão em níveis distintos. É um equívoco, portanto, trata-los como se estivessem no mesmo plano [...]”. MITIDIERO, Daniel. Precedentes: da persuasão à vinculação. $3^{a}$ ed. São Paulo: Revista dos Tribunais, 2018, p. 102-104. 
Corte acaba por proferir decisões plurais que, em alguns casos, impossibilitam completamente a formação de precedentes e, noutros, tornam a atividade interpretativa exercício inexorável à aplicação dos precedentes - excessivamente difícil.

Haja vista a anterior abordagem teórica sobre estrutura das decisões da Corte Suprema objeto de análise, resta-nos o estudo empírico. Debruçar-se-á sobre a decisão proferida pelo Supremo Tribunal Federal no HC $126.292^{41}$, que se presta à demonstração da crítica proposta do presente trabalho, exemplificando uma situação de complexidade interpretativa, advinda da pluralidade, capaz de impedir ou dificultar excessivamente a delimitação da ratio decidendi.

O caso, que teve ampla repercussão social, diz respeito ao Habeas Corpus impetrado em face de ato praticado pelo Relator do $\mathrm{HC} \mathrm{N}^{\circ} 313.021$ do Superior Tribunal de Justiça. ${ }^{42} \mathrm{O}$ recurso tinha como objeto a (in)constitucionalidade da execução provisória de acordão penal condenatório à luz do direito fundamental à presunção da inocência. A Corte mediante voto da maioria denegou a ordem, revogando a antecipação de tutela deferida, fixando a tese de que "a execução provisória de acórdão penal condenatório proferido em grau de apelação, ainda que sujeito a recurso especial ou extraordinário, não compromete o princípio constitucional da presunção de inocência”, vencidos os Ministros Rosa Weber, Marco Aurélio, Celso de Mello e Ricardo Lewandowski (Presidente).

O julgamento em questão se mostra de grande relevância ao estudo na medida em que a decisão contém diversos fundamentos capazes de sustentar a solução do caso e da "tese" eleita, porém nenhum deles acompanhado pela maioria da Corte. Acontece que alguns fundamentos adotados podem ser interpretados como decorrentes de outros. Isso significa, como analisar-se-á, que se torna extremamente difícil a tarefa do intérprete em extrair a ratio decidendi dessa decisão. A partir de agora se pretende demonstrar essa diversidade trazendo a síntese dos seis votos à denegação da ordem.

O relator Ministro Teori Zavascki sustenta seu voto com base em dois fundamentos: (a) deve-se relativizar o princípio da presunção da inocência em razão da

\footnotetext{
${ }^{41}$ BRASIL, Supremo Tribunal Federal. Habeas Corpus 126.292. Tribunal Pleno Relator Ministro Teori Zavascki. Julgado em 17 de fevereiro de 2016. Lex: acórdão. Disponível em: <www.stf.jus.br>. Acesso em: 24 mai. 2020.

${ }^{42}$ Cabe ressaltar que o presente artigo não tem o objetivo, nem de adentrar-se na questão de mérito atinente ao direito penal e ao direito processual penal, nem de analisar a correção ou incorreção das premissas utilizadas para sustentar os argumentos dos julgadores.
} 
função dos recursos extraordinários, de modo que é no segundo grau de jurisdição que ocorre o exaurimento da cognição sobre fatos e provas; (b) a atribuição unicamente de efeito devolutivo aos recursos extraordinários harmoniza o princípio da presunção da inocência com o princípio da efetivação da lei penal. ${ }^{43} \mathrm{O}$ Ministro Edson Fachin sustenta que a função das Cortes é capaz de estabelecer limite ao princípio da presunção da inocência, sendo que às instâncias ordinárias cabe analisar provas e fatos, de modo que o acesso às instâncias extraordinárias visa oportunizar às Cortes Supremas o exercício de seus papéis. ${ }^{44} \mathrm{O}$ Ministro Luiz Roberto Barroso apresenta quatro fundamentos à denegação da ordem, sendo eles: (a) o pressuposto para prisão não é o trânsito em julgado, mas sim a ordem escrita e fundamentada (existe diferença entre o instituto da culpabilidade e a prisão) ${ }^{45}$; (b) a presunção da inocência é um princípio e admite ponderação, de modo que ele se desenvolve em graus durante a tramitação do processo $^{46}$; (c) a execução provisória da pena constitui exigência de ordem pública ${ }^{47}$; (d) deve ser garantida a execução provisória da pena, pois tutela o equilíbrio e funcionalidade do sistema de justiça criminal e diminui a seletividade

\footnotetext{
${ }^{43} \mathrm{Em}$ seu voto, o Ministro Teori Zavascki expõe o primeiro argumento da seguinte forma: "Nessas circunstâncias, tendo havido, em segundo grau, um juízo de incriminação do acusado, fundado em fatos e provas insuscetíveis de reexame pela instância extraordinária, parece inteiramente justificável a relativização e até mesmo a própria inversão, para o caso concreto, do princípio da presunção de inocência até então observado". E, quanto ao segundo argumento, expõe que: "A retomada da tradicional jurisprudência, de atribuir efeito apenas devolutivo aos recursos especial e [...] é, sob esse aspecto, mecanismo legítimo de harmonizar o princípio da presunção de inocência com o da efetividade da função jurisdicional do Estado". (BRASIL, Supremo Tribunal Federal. Habeas Corpus 126.292. Tribunal Pleno Relator Ministro Teori Zavascki. Julgado em 17 de fevereiro de 2016. Lex: acórdão. Disponível em: 〈www.stf.jus.br〉. Acesso em: 24 mai. 2020).

${ }^{44}$ A síntese do argumento do Ministro Edson Fachin pode ser observada quando assevera que: "As instâncias ordinárias, portanto, são soberanas no que diz respeito à avaliação das provas e à definição das versões fáticas apresentadas pelas partes. Ainda, o acesso via recurso ao Supremo Tribunal Federal e ao Superior Tribunal de Justiça se dá em caráter de absoluta excepcionalidade. [...] O acesso individual às instâncias extraordinárias visa a oportunizar a esta Suprema Corte e ao Superior Tribunal de Justiça exercerem seus papéis de estabilizadores, uniformizadores e pacificadores da interpretação das normas constitucionais e do direito infraconstitucional". (Ibid, loc. cit.).

${ }^{45}$ Conforme o Ministro Luiz Roberto Barroso: “O pressuposto para a decretação da prisão no direito brasileiro não é o esgotamento de qualquer possibilidade de recurso em face da decisão condenatória, mas a ordem escrita e fundamentada da autoridade judiciária competente". (BRASIL, Supremo Tribunal Federal. Habeas Corpus 126.292. Tribunal Pleno Relator Ministro Teori Zavascki. Julgado em 17 de fevereiro de 2016. Lex: acórdão. Disponível em: <www.stf.jus.br>. Acesso em: 24 mai. 2020).

${ }^{46} \mathrm{O}$ Ministro expõe que: "Há, desse modo, uma ponderação a ser realizada. Nela, não há dúvida de que o princípio da presunção de inocência ou da não culpabilidade adquire peso gradativamente menor na medida em que o processo avança, em que as provas são produzidas e as condenações ocorrem". (Ibid., loc. cit.).

47 “É possível, subsidiariamente, construir outro fundamento, de estatura infraconstitucional: com o acórdão penal condenatório proferido em grau de apelação, a execução provisória da pena passa a constituir, em regra, exigência de ordem pública, necessária para assegurar a credibilidade do Poder Judiciário e do sistema penal”. (Ibid. loc. cit.).
} 
do sistema penal. ${ }^{48}$ O Ministro Luiz Fux utiliza-se de dois fundamentos: (a) existência de “coisa julgada singular", que acoberta as decisões proferidas em segundo grau de jurisdição, recaindo exclusivamente sobre fatos; (b) o princípio da presunção da inocência cessa no segundo grau de jurisdição. ${ }^{49}$ A Ministra Cármen Lúcia sustenta que culpa e condenação são institutos diferentes, de modo que é a condenação que leva ao início do cumprimento da pena, não afetando, portanto, o princípio da não culpabilidade. ${ }^{50}$ Por fim, o Ministro Gilmar Mendes fundamenta seu voto na premissa de que a presunção da inocência se desenvolve em graus, estando presente em menor grau no julgamento de recursos extraordinários. ${ }^{51}$

Conforme o detalhamento dos votos dos seis julgadores chega-se ao seguinte panorama, quanto aos fundamentos genericamente considerados:

(a) Fundamento "ponderação do princípio da presunção da inocência": quatro votos - Ministros Teori Zavascki, Luiz Roberto Barroso, Luiz Fux e Gilmar Mendes;

(b) Fundamento "função das Cortes e dos recursos extraordinários": dois votos - Ministros Teori Zavascki e Edson Fachin;

\footnotetext{
${ }^{48}$ Tutela o equilíbrio e a funcionalidade da justiça criminal, pois, segundo o Ministro: "Em primeiro lugar, com esta nova orientação, reduz-se o estímulo à infindável interposição de recursos inadmissíveis. [...] Em segundo lugar, restabelece-se o prestígio e a autoridade das instâncias ordinárias, algo que há muito se perdeu no Brasil". E, diminui a seletividade penal na medida em que: "Atualmente, como já demonstrado, permite-se que as pessoas com mais recursos financeiros, mesmo que condenadas, não cumpram a pena ou possam procrastinar a sua execução por mais de 20 anos. [...] A alteração da compreensão do STF acerca do momento de início de cumprimento da pena deverá ter impacto positivo sobre o número de pessoas presas temporariamente [...], bem como produzirá um efeito republicano e igualitário sobre o sistema". (Ibid. loc. cit.).

${ }^{49}$ Acerca do fundamento atinente à existência de uma "coisa julgada singular" propõe o Ministro Luiz Fux que: "A coisa julgada está intimamente vinculada à ideia da imutabilidade da decisão. Coisa julgada significa a imutabilidade da decisão ou a indiscutibilidade de alguns capítulos da decisão. E é exatamente o que ocorre no processo penal [...] com relação àquela matéria fático-probatória. Há uma coisa julgada singular, porque, aquilo ali, em regra, é imutável, indiscutível, porque não é passível de análise no Tribunal Superior. Só se devolvem questões constitucionais e questões federais". E, no que tange ao momento em que cessa a presunção de inocência, afirma: "O desenvolvimento da força normativa da Constituição, nesse aspecto, está em que a presunção de inocência cessa a partir do momento em que se comprova a culpabilidade do agente, máxime, em segundo grau de jurisdição, encerrando um julgamento impassível de ser modificado pelos Tribunais Superiores". (Ibid. loc. cit.).

${ }^{50}$ Conforme voto da Ministra Cármen Lúcia: “[...] a interpretação da Constituição no sentido de que ninguém pode ser considerado culpado até o trânsito em julgado da sentença penal condenatória haveria de ser lido e interpretado no sentido de que ninguém poderá ser considerado culpado e não condenado". (Ibid., loc. cit.).

${ }^{51}$ Com esse fundamento o Ministro Gilmar Mendes expõe suas razões: "Ou seja, é natural à presunção de não culpabilidade evoluir de acordo com o estágio do procedimento. Desde que não se atinja o núcleo fundamental, o tratamento progressivamente mais gravoso é aceitável. [...] Conforme se avança [o processo] e a culpa vai ficando demonstrada, a lei poderá impor tratamento algo diferenciado". (BRASIL, Supremo Tribunal Federal. Habeas Corpus 126.292. Tribunal Pleno Relator Ministro Teori Zavascki. Julgado em 17 de fevereiro de 2016. Lex: acórdão. Disponível em: <www.stf.jus.br>. Acesso em: 24 mai. 2020).
} 
(c) Fundamento "condenação (ou prisão) diferencia-se da culpabilidade": dois votos - Ministros Luiz Roberto Barroso e Cármen Lúcia;

(d) Fundamento "execução provisória da pena como exigência de ordem pública": um voto - Ministro Luiz Roberto Barroso;

(e) Fundamento "execução provisória da pena como garantia do equilíbrio e funcionalidade da justiça criminal e como forma de diminuição da seletividade do sistema penal": um voto - Ministro Luiz Roberto Barroso;

(f) Fundamento "coisa julgada sobre fatos": um voto - Ministro Luiz Fux.

Considerando o total de dez votos e que nenhum fundamento obteve a aderência da maioria da Corte, o caso em questão figura-se como exemplo típico de uma decisão plural. Chega-se a presente conclusão a partir da consideração de que a solução encontrada pela Corte (pautada no entendimento de que a execução provisória no juízo penal não compromete o princípio constitucional da presunção de inocência) pode ser sustentada por diversos fundamentos não majoritários ou unânimes. Dito de outro modo, a Corte chegou a uma conclusão majoritária, sustentada por fundamentos não majoritários.

Porém, se pode, com certo esforço interpretativo, extrair um denominador comum do raciocínio da Corte, que se pauta na existência de competências (funções) distintas entres as instâncias. O ponto de contato entre as diversas frentes argumentativas adotadas pelos Ministros foi estabelecer a existência de limitação cognitiva das Cortes Supremas de tal modo que não cabe a elas atribuir valor distinto aos fatos já examinados pelas instâncias inferiores. ${ }^{52}$ Assim, chegam a conclusão de que a execução provisória não afronta o princípio da presunção da inocência. Note-se que, pra tanto, é necessário realizar interpretação adscritiva de sentido ao texto da decisão oportunidade em que é formado o precedente.

É interessante refletir que, muito embora essa decisão seja claramente pluralizada nos seus fundamentos, teve enorme aderência pelas instâncias inferiores que

\footnotetext{
52 Assim se pode observar em algumas passagens, muito embora não seja o argumento central, nos votos dos Ministros Luiz Roberto Barroso e Gilmar Mendes, nessa ordem: “os recursos extraordinário e especial não se prestam a rever as condenações, mas apenas a tutelar a higidez do ordenamento jurídico constitucional e infraconstitucional" (p. 41) e "na hipótese que estamos analisando, ainda que a condenação não tenha transitado em julgado, já foi estabelecida pelas instâncias soberanas para análise dos fatos” (p. 68). (BRASIL, Supremo Tribunal Federal. Habeas Corpus 126.292. Tribunal Pleno Relator Ministro Teori Zavascki. Julgado em 17 de fevereiro de 2016. Lex: acórdão. Disponível em: <www.stf.jus.br>. Acesso em: 24 mai. 2020).
} 
aplicaram de forma silogística ${ }^{53}$ a tese fixada pelo Supremo Tribunal Federal. Somente no Rio Grande do Sul no período de um ano desde a publicação da decisão foram julgados 902 casos em que se fez valer o entendimento firmado pela Corte Suprema, tornando evidente o respeito à autoridade institucional desse tribunal. ${ }^{54}$

Em suma, debruçar-se empiricamente sobre a decisão analisada é especialmente intrigante do ponto de vista da necessária otimização pelo próprio Supremo Tribunal Federal de suas manifestações, a fim de que o caso seja um pretexto para que a Corte cumpra sua função de outorgar adequada interpretação ao direito. ${ }^{55}$ No caso citado a Corte perdeu uma ótima oportunidade de manifestar-se de maneira uníssona, com vistas ao estabelecimento de uma ratio decidendi bem definida, estendendo o âmbito de aplicação de seu julgado.

\section{CONSIDERAÇÕES FINAIS}

Tomada a premissa (a) que o precedente não é a decisão propriamente dita, mas decorre de apenas parte (as razões universalizáveis) e (b) que o a decisão é proferida em produto textual (e, enquanto tal, duplamente indeterminado), fica evidente que para a formação do precedente é necessária a interpretação da decisão (texto-base), para a extração do procedente (texto-produto). Nesse processo interpretativo, deve-se considerar que as questões levadas à análise das Cortes Supremas em geral gozam de grande complexidade, razão pela qual dificilmente a aplicação do direito se dá de modo subsuntivo ou literal. Assim, o intérprete diante de um caso busca em decisão anterior (cuja situação a ser decidida seja analógica), razões universalizáveis. Nessa busca ocorre a extração da ratio decidendi, adscrevendo-se sentido (significado) e função (diminuição da indeterminação do direito) à parcela da decisão (razões universalizáveis) anteriormente proferida. No entanto, sendo o

\footnotetext{
${ }^{53}$ Nesse sentido é a crítica da doutrinadora Thaís Ferraz que salienta: "Equipara-se a tese jurídica, tal como vem sendo enunciada, a uma edição de norma, porém pelo Poder Judiciário, cuja aplicação tende a ocorrer da mesma forma que se faz incidir uma lei. Adotada, porém, a verdadeira ratio decidendi do precedente pelo seu intérprete, a aplicação poderá ser muito mais útil, sistêmica e mesmo abrangente [...]”. FERRAZ, Thaís Schilling. Ratio Decidendi x Tese Jurídica. A busca pelo elemento vinculante do precedente brasileiro. Revista de Processo, v. 265, mar., p.419-441, 2017.

${ }^{54}$ JARDIM, Augusto Tanger. Cortes Supremas e Cortes de Justiça: a necessidade de ressignificação do sistema judiciário brasileiro. In.: ARENHART, Sérgio Cruz; MITIDIERO, Daniel (Coord.). O Processo Civil entre a Técnica Processual e a Tutela dos Direitos: estudos em homenagem a Luiz Guilherme Marinoni. São Paulo: Revista dos Tribunais, 2017, p. 944.

${ }^{55}$ MITIDIERO, Daniel. Cortes Superiores e Cortes Supremas: do controle à interpretação, da jurisprudência ao precedente. $3^{\text {a }}$ ed. São Paulo: Revista dos Tribunais, 2017, p. 80-81.
} 
precedente formado a partir da decisão, é imprescindível que se tenha clareza acerca de qual decisão pode formar um precedente e qual sua parcela (seus elementos) servem a este propósito. Não sendo a decisão apta a formar precedente (dimensão externa), ou não possuindo os elementos necessários (dimensão interna), ela jamais poderá ser considerada (para quem cogita da equivalência) ou formar um precedente (para quem, como aqui, cogita de uma distinção).

Ocorre que, para que esse processo interpretativo de formação do precedente não seja deixado ao livre arbítrio do intérprete, é necessário estabelecer parâmetros claros a respeito do tema. O ponto suscitado aqui tem por condão apenas chamar a atenção para que seja adotado um esforço analítico e lógico na formação de conteúdo jurídico pelas Cortes. Esse esforço, materializado na forma do modelo proposto, pode ser empreendido tanto na tomada de decisão, quanto na adoção do método de extração da ratio decidendi (favorecendo o processo de interpretação analógica que demanda a aplicação do precedente).

Por fim, é importante referir que a existência de decisões plurais não representa necessariamente um problema para o sistema de precedentes. A existência de uma decisão plural pode ser o sinal de que a questão ainda não está suficientemente debatida para a formação de um precedente a seu respeito. A prestação da tutela jurisdicional é dada, mas os seus efeitos prospectivos (típicos dos precedentes) não são atingidos. No entanto, não tendo sido formado o precedente, nada impede que novos análogos casos cheguem às Cortes Supremas para análise e, quem sabe, formação de um consenso. $\mathrm{O}$ verdadeiro risco da decisão plural é tomar o resultado do julgamento para a formação do precedente, pois, nesta situação, estar-se-ia propondo uma solução a priori para casos análogos sem a devida justificação, na medida em que os fundamentos (em face da pluralidade) seriam desconhecidos.

Por outro lado, se é bem verdade que o Supremo Tribunal Federal tem grande autoridade institucional dentro do sistema jurídico brasileiro, ele deve fazer valer o seu posicionamento hierárquico comunicando-se em uma só "voz", porque "[...] na realidade do julgamento colegiado no STF, fundada num arranjo decisório marcado pela agregação das 
posições individuais sem a previa deliberação, a Corte se comunica mediante várias vozes, o que, em grande medida, obsta que se compreenda o entendimento institucional", 56

A capacidade da Corte em manifestar-se de forma uníssona pode ser demonstrada no julgamento do "caso sucessão do companheiro" (RE 878.694 ${ }^{57}$ ). Nessa decisão foi fixada a seguinte tese: "no sistema constitucional vigente, é inconstitucional a distinção de regimes sucessórios entre cônjuges e companheiros, devendo ser aplicado, em ambos os casos, o regime estabelecido no art. 1.829 do CC/2002”. O fundamento majoritário pautou-se na impossibilidade de tratamento desigual entre entidades familiares que importem no privilégio de uma constituição familiar em detrimento de outra. $\mathrm{O}$ reflexo no sistema jurídico desse julgamento, em razão da estrutura decisória que permite a extração e interpretação da ratio decidendi facilitada, é a ampliação do seu âmbito de aplicação, para além da sucessão legítima. Isso quer dizer que, aplicando-se o decidido nos autos do RE 878.694, se poderá discutir se o companheiro é herdeiro necessário ou apenas herda como se herdeiro necessário fosse - de modo a, por exemplo, implicar limitações das disposições testamentárias -, bem como se o direito real de habitação outrora previsto expressamente no Código Civil sem limitação temporal somente ao cônjuge supérstite também estende-se ao companheiro, dentre outras questões que poderão decorrer do entendimento da Corte de que é inconstitucional diferenciações que hierarquizem uma instituição familiar.

Assim, sobretudo a partir de uma investigação prática, pode-se perceber que a estrutura das decisões do Supremo Tribunal Federal reflete em como a Corte se comunica, de modo que se forem pautadas em fundamentos plurais, não majoritários, a extração da ratio se demonstra excessivamente difícil e, em alguns casos, impossível. Por outro lado, o Supremo Tribunal Federal tem plena capacidade de estruturar suas decisões vocacionadas à formação de precedentes, demonstrando preocupação com sua função de promover tutela aos direitos na dimensão geral, dando unidade ao direito, mediante adequada interpretação dos textos normativos.

\footnotetext{
${ }^{56}$ ZARONI, Bruno Marzullo. Cortes Supremas e Cortes de Justiça: a necessidade de ressignificação do sistema judiciário brasileiro. In.: ARENHART, Sérgio Cruz; MITIDIERO, Daniel (Coord.). O Processo Civil entre a Técnica Processual e a Tutela dos Direitos: estudos em homenagem a Luiz Guilherme Marinoni. São Paulo: Revista dos Tribunais, 2017, p. 964.

${ }^{57}$ BRASIL, Supremo Tribunal Federal. Recurso Extraordinário 878.694. Tribunal Pleno Relator Ministro Luiz Roberto Barroso. Julgado em 10 de maio de 2017. Lex: acórdão. Disponível em: <www.stf.jus.br>. Acesso em: 24 mai. 2020.
} 


\section{REFERÊNCIAS}

ALEXY, Robert. Teoria da argumentação jurídica - A teoria do discurso racional como teoria da fundamentação jurídica. 3. ed. Trad. Zilda Hutchinson Schild Silva. Rio de Janeiro: Forense, 2011.

ÁVILA, Humberto. Função da ciência do direito tributário: do formalismo epistemológico ao estruturalismo argumentativo. Revista Direito Tributário Atual, n. 29, p. 181-204, 2013.

. Teoria dos Princípios: da definição à aplicação dos princípios jurídicos. $19^{\mathrm{a}}$ ed. São Paulo: Malheiros, 2019.

BRASIL, Supremo Tribunal Federal. Habeas Corpus 126.292. Tribunal Pleno Relator Ministro Teori Zavascki. Julgado em 17 de fevereiro de 2016. Lex: acórdão. Disponível em: <www.stf.jus.br>. Acesso em: 24 mai. 2020.

Recurso Extraordinário878.694. Tribunal Pleno Relator Ministro Luiz Roberto Barroso. Julgado em 10 de maio de 2017. Lex: acórdão. Disponível em: <www.stf.jus.br>. Acesso em: 24 mai. 2020.

CAMARA, Alexandre Freitas. Levando os padrões decisórios a sério: formação e aplicação de precedentes e enunciados de súmula. São Paulo: Atlas, 2018.

CHIASSONI, Pierluigi. Il Precedente Giudiziale: tre esercizi di disincanto. In.: COMANDUCCI, Paolo; GUASTINI, Riccardo (Coord.). Analisi e Diritto: ricerche di giurisprudenza analitica. Torino: G. Giappichelli Editore, 2004.

DAVIS, John F.; REYNOLDS, William L. Juridical Cripples: Plurality opinions in the supreme court. Duke Law Journal, v. 59, 1974.

DIDIER JR., Fredie; BRAGA, Paula Sarno; OLIVEIRA, Rafael Alexandria de. Curso de Direito Processual Civil: teoria da prova, direito probatório, decisão, precedente, coisa julgada e tutela provisória. 14ª ed. Salvador: JusPodivm, 2019.

FERRAZ, Thaís Schilling. A Construção da Motivação nas Decisões Colegiadas: o importante papel da majority opinion em um sistema de precedentes. Revista de Processo, v. 282, ago., p.435-451, 2018.

Ratio Decidendi x Tese Jurídica. A busca pelo elemento vinculante do precedente brasileiro. Revista de Processo, v. 265, mar., p.419-441, 2017. 
FINE, Toni M. Introdução ao sistema jurídico Anglo-Americano. Tradução: Eduardo Saldanha. São Paulo: VWF Martins Fontes, 2011.

GOODHART, Arthur. Determining the Ratio Decidendi of a Case. Yale Law Journal, v. 40, 1930.

GUASTINI, Riccardo. Das Fontes às Normas. Tradução: Heleno Taveira Tôrres. São Paulo: Quartier Latin, 2005. Interpretare e Argomentare. Milano: Giuffrè, 2011.

HOCHSCHILD, Adam S. The Modern Problem of Supreme Court Plurality Decision: Interpretation In Historical Perspective. Washington University Journal of Law \& Policy, vol. 4., 2000.

JARDIM, Augusto Tanger. Cortes Supremas e Cortes de Justiça: a necessidade de ressignificação do sistema judiciário brasileiro. In.: ARENHART, Sérgio Cruz; MITIDIERO, Daniel (Coord.). O Processo Civil entre a Técnica Processual e a Tutela dos Direitos: estudos em homenagem a Luiz Guilherme Marinoni. São Paulo: Revista dos Tribunais, 2017.

KELSEN, Hans. Teoria Pura do Direito. Tradução: João Baptista Machado. $8^{a}$ ed. São Paulo: WMF Martins Fontes, 2009.

TARUFFO, Michele. Il Controllo di Razionalità della Decisione fra Logica, Retorica e Dialettica. Revista de Processo, v. 143, jan., p.65, 2007. Precedente e Jurisprudência. Revista de Processo, v. 199, set., p.139, 2011. . A motivação da sentença civil [La motivazione della sentenza civile - 1975]. Trad. Daniel Mitidiero, Rafael Abreu, Vitor de Paula Ramos. São Paulo: Marcial Pons, 2015. MACCORMICK, Neil. Argumentação Jurídica e Teoria do Direito. Tradução: Weldéa Barcellos. $2^{\mathrm{a}}$ ed. São Paulo: WMF Martins Fontes, 2009.

MARINONI, Luiz Guilherme. Julgamento nas Cortes Supremas: precedente e decisão do recurso diante do novo CPC. Ed. São Paulo: Revista dos Tribunais, 2015. Precedentes Obrigatórios. $6^{\text {a }}$ ed. São Paulo: Revista dos Tribunais, 2019.

MITIDIERO, Daniel. Cortes Superiores e Cortes Supremas: do controle à interpretação, da jurisprudência ao precedente. $3^{\mathrm{a}}$ ed. São Paulo: Revista dos Tribunais, 2017.

Precedentes: da persuasão à vinculação. $2^{\mathrm{a}}$ ed. São Paulo: Revista dos Tribunais, 2018 . 
MOTTA, Otávio Verdi. Justificação da decisão judicial: a elaboração da motivação e a formação de precedente. São Paulo: Revista dos Tribunais, 2015.

TARELLO, Giovanni. L'interpretazione della Legge. Milano: Giuffrè, 1980.

WASSERSTROM, Richard A. The judicial decision: toward a theory of legal justification. Stanford: Stanford University Press, 1961, p. 27.

ZANETI JR., Hermes. O Valor Vinculante dos Precedentes: teoria dos precedentes normativos formalmente vinculantes. $4^{\mathrm{a}}$ ed. Salvador: JusPodivm, 2019.

ZARONI, Bruno Marzullo. Cortes Supremas e Cortes de Justiça: a necessidade de ressignificação do sistema judiciário brasileiro. In.: ARENHART, Sérgio Cruz; MITIDIERO, Daniel (Coord.). O Processo Civil entre a Técnica Processual e a Tutela dos Direitos: estudos em homenagem a Luiz Guilherme Marinoni. São Paulo: Revista dos Tribunais, 2017. 